University of Montana

ScholarWorks at University of Montana

Ecosystem and Conservation Sciences Faculty

Publications

Ecosystem and Conservation Sciences

2006

\title{
Nutrient Regulation of Organic Matter Decomposition in a Tropical Rain Forest
}

Cory C. Cleveland

The University of Montana, cory.cleveland@umontana.edu

Sasha C. Reed

Alan R. Townsend

Follow this and additional works at: https://scholarworks.umt.edu/decs_pubs

Part of the Ecology and Evolutionary Biology Commons

Let us know how access to this document benefits you.

\section{Recommended Citation}

Cleveland, Cory C.; Reed, Sasha C.; and Townsend, Alan R., "Nutrient Regulation of Organic Matter Decomposition in a Tropical Rain Forest" (2006). Ecosystem and Conservation Sciences Faculty Publications. 11.

https://scholarworks.umt.edu/decs_pubs/11

This Article is brought to you for free and open access by the Ecosystem and Conservation Sciences at ScholarWorks at University of Montana. It has been accepted for inclusion in Ecosystem and Conservation Sciences Faculty Publications by an authorized administrator of ScholarWorks at University of Montana. For more information, please contact scholarworks@mso.umt.edu. 


\title{
NUTRIENT REGULATION OF ORGANIC MATTER DECOMPOSITION IN A TROPICAL RAIN FOREST
}

\author{
Cory C. Cleveland, ${ }^{1,3}$ Sasha C. Reed, ${ }^{2}$ and Alan R. Townsend \\ ${ }^{1}$ Institute of Arctic and Alpine Research (INSTAAR), University of Colorado, Boulder, Colorado 80303 USA \\ ${ }^{2}$ Department of Ecology and Evolutionary Biology, and INSTAAR, University of Colorado, Boulder, Colorado, USA
}

\begin{abstract}
Terrestrial biosphere-atmosphere $\mathrm{CO}_{2}$ exchange is dominated by tropical forests, so understanding how nutrient availability affects carbon (C) decomposition in these ecosystems is central to predicting the global $\mathrm{C}$ cycle's response to environmental change. In tropical rain forests, phosphorus (P) limitation of primary production and decomposition is believed to be widespread, but direct evidence is rare. We assessed the effects of nitrogen $(\mathrm{N})$ and $\mathrm{P}$ fertilization on litter-layer organic matter decomposition in two neighboring tropical rain forests in southwest Costa Rica that are similar in most ways, but that differ in soil P availability. The sites contain 100-200 tree species per hectare and between species foliar nutrient content is variable. To control for this heterogeneity, we decomposed leaves collected from a widespread neotropical species, Brosimum utile. Mass loss during decomposition was rapid in both forests, with $B$. utile leaves losing $>80 \%$ of their initial mass in $<300$ days. High organic matter solubility throughout decomposition combined with high rainfall support a model of litter-layer decomposition in these rain forests in which rapid mass loss in the litter layer is dominated by leaching of dissolved organic matter (DOM) rather than direct $\mathrm{CO}_{2}$ mineralization. While $\mathrm{P}$ fertilization did not significantly affect mass loss in the litter layer, it did stimulate P immobilization in decomposing material, leading to increased $\mathrm{P}$ content and a lower $\mathrm{C}: \mathrm{P}$ ratio in soluble DOM. In turn, increased $\mathrm{P}$ content of leached DOM stimulated significant increases in microbial mineralization of DOM in P-fertilized soil. These results show that, while nutrients may not affect mass loss during decomposition in nutrient-poor, wet ecosystems, they may ultimately regulate $\mathrm{CO}_{2}$ losses (and hence $\mathrm{C}$ storage) by limiting microbial mineralization of DOM leached from the litter layer to soil.
\end{abstract}

Key words: Brosimum utile; decomposition; dissolved organic carbon (DOC); dissolved organic matter (DOM); fertilization; leaching; nitrogen; nutrient limitation; phosphorus; tropical rain forest.

\section{INTRODUCTION}

The amount of carbon (C) that is stored in any ecosystem represents a balance between net primary productivity (NPP) and C loss via organic matter decomposition, and therefore accurate predictions about $\mathrm{C}$ cycle responses to global change require an understanding of the factors that regulate decomposition. Because tropical forests contain up to $40 \%$ of terrestrial C biomass and account for one-third of annual biosphereatmosphere $\mathrm{CO}_{2}$ exchange (Field et al. 1998, Phillips et al. 1998), even small changes in decomposition rates could profoundly alter atmospheric composition and climate at a global scale (Shukla et al. 1990, Townsend et al. 1992). Thus, identifying the factors that regulate organic matter decomposition in these highly productive, C-rich ecosystems is critical to our understanding of the current and future global $\mathrm{C}$ balance.

Conceptual and analytical models developed from a long history of research suggest three main controls on decomposition in terrestrial ecosystems: (1) the quality

Manuscript received 1 April 2005; revised 15 June 2005; accepted 1 August 2005. Corresponding Editor: J. B. Yavitt.

${ }^{3}$ E-mail: Cory.Cleveland@colorado.edu and quantity of the organic matter being decomposed, (2) the physical environment (e.g., temperature, precipitation, soil type), and more recently (3) the nature and identity of the soil organisms decomposing the organic material (Meentemeyer 1978, Swift et al. 1979, Chapin et al. 2002). One factor, substrate quality, describes the decomposability of organic matter based on its chemical composition. However, while C chemistry partly influences substrate quality, the nutrient content and carbon-to-nutrient stoichiometry of decomposing material are equally important determinants (Melillo et al. 1982). For example, "low quality" organic material is relatively lignin rich and nutrient poor, and decomposes slowly (Meentemeyer 1978). In contrast, "high quality" organic matter may have similar C chemistry, but higher relative nutrient availability may fuel more rapid microbial decomposition of C-rich organic material (Melillo et al. 1982, Parton et al. 1994). Thus, the element content of organic material strongly influences rates of decomposition; if the nutrient demand of microbes decomposing nutrient-poor organic matter outpaces mineralization, then nutrient limitation may constrain decomposition (Vitousek and Howarth 1991).

Nitrogen $(\mathrm{N})$ commonly limits decomposition and other ecosystem processes in temperate ecosystems 
(Aber et al. 1991, Vitousek and Howarth 1991). However, many tropical rain forests lie on highly weathered soils that are relatively $\mathrm{N}$ rich (Martinelli et al. 1999), but that are depleted in "rock-derived" essential nutrients (Walker and Syers 1976, Sanchez et al. 1982). As a result, some evidence suggests that phosphorus (P) limits ecosystem processes in tropical rain forests more often than N (Uehara and Gilman 1981, Vitousek 1984, Vitousek and Sanford 1986, Herbert and Fownes 1995). For example, on a soil chronosequence in Hawaii, Hobbie and Vitousek (2000) found that where P limits annual NPP, elevated P (in litter) and elevated $\mathrm{N}+\mathrm{P}$ (in soil) increased decomposition rates. However, despite the widespread belief that $\mathrm{P}$ availability limits NPP in tropical rain forests, direct experimental evidence of $\mathrm{P}$ limitation is rare, and the nature and extent of nutrient limitation of decomposition in tropical ecosystems is poorly understood.

The objective of this study was to investigate the effects of nutrient availability on litter layer organic matter decomposition in two adjacent tropical rain forests that differ in soil $\mathrm{P}$ availability. In addition, while estimates of decomposition are commonly reported as a single empirical constant representing mass loss rate (i.e., $k$ in the expression $\mathrm{e}^{-k t}$; Olson 1963), decomposition includes two distinct mass loss vectors: $\mathrm{CO}_{2}$ mineralization in the litter layer and leaching (e.g., Yavitt and Fahey 1986, Currie and Aber 1997). The first of these, mineralization in the litter layer, represents a biologically mediated, chemical transformation of organic matter to $\mathrm{CO}_{2}$. In contrast, leaching does not transform organic material per se, but merely redistributes $\mathrm{C}$ from the litter layer to the soil. Thus, while "mass loss" is typically a single measured variable, it integrates two fundamentally different processes that may vary in their response to nutrients.

For example, in dry systems (where leaching is a relatively small mass loss vector) organic matter mass loss rates are most likely to be nutrient limited at the site of $\mathrm{CO}_{2}$ mineralization (i.e., in the litter layer). Alternatively, in wet systems (where leaching is a more dominant mass loss vector) nutrient availability may not limit mass loss rates themselves, but may ultimately limit microbial mineralization of transported dissolved organic matter (DOM) at the site of DOM delivery (i.e., in the soil). Thus, in addition to investigating the effects of nutrient availability on organic matter mass loss, we were equally interested in the effects of nutrient availability on the microbial mineralization of DOM leached from litter to soil. While most previous decomposition studies have not explicitly considered the effects of nutrient availability on these two fundamentally different mechanisms, such a distinction is critical to understanding how low nutrient availability regulates $\mathrm{C}$ cycling and storage in wet, productive ecosystems.

\section{Materials and Methods Site description}

Our study sites were two adjacent tropical rain forests on the Osa Peninsula, southwest Costa Rica. The two forests, located on the north end of the Osa Peninsula in the Golfo Dulce Forest Reserve $\left(8^{\circ} 43^{\prime} \mathrm{N}\right.$, $83^{\circ} 37^{\prime} \mathrm{W}$ ), are several hundred meters apart, and contain diverse primary lowland tropical rain forest. The sites are similar in most ways, including mean annual temperature (MAT), mean annual precipitation (MAP), elevation, and species composition (Appendix A). However, the sites are characterized by distinct soil orders and categories of parent material. One site (ultisol forest, hereafter UF) has ultisols that developed on a steeply dissected landscape in the Osa basaltic complex (Bern et al. 2005). The other site (alluvial forest, hereafter AF) occupies an ancient floodplain, and contains less weathered, more organic matter rich and nutrient-rich mollisols that developed from a complex mixture of Quaternary alluvium dominated by Osa basalt deposited within the last 20000 years (Bern et al. 2005).

\section{Experimental design}

To test the effects of nutrient availability on decomposition, we fertilized plots with $\mathrm{N}$ and $\mathrm{P}$ in a full factorial design (10 replicates per treatment, per site). Plots were randomly selected to receive treatments, and were fertilized twice per year (in January during the dry season and in June during the wet season) by hand broadcasting $\mathrm{N}\left(150 \mathrm{~kg} \mathrm{~N}^{-1} \mathrm{yr}^{-1}\right.$ as $\left.\mathrm{NH}_{4} \mathrm{NO}_{3}\right), \mathrm{P}$ (150 kg P ha ${ }^{-1} \mathrm{yr}^{-1}$ as $\mathrm{KH}_{2} \mathrm{PO}_{4}$ ), or $\mathrm{N}$ and $\mathrm{P}$ in combination (150 kg ha ${ }^{-1} \mathrm{yr}^{-1} \mathrm{~N}$ and $\mathrm{P}$ ). Ten control plots at each site were not fertilized. Fertilized plots received $\mathrm{N}$, $\mathrm{P}$, or $\mathrm{N}+\mathrm{P}$ at a high rate and at a $1: 1$ ratio to account for the high $\mathrm{P}$ sorption capacity of the ultisol soil (Oberson et al. 1997, Townsend et al. 2002a), and to ensure that all possible nutrient constraints by $\mathrm{N}$ and P were removed (e.g., Hobbie and Vitousek 2000). Fertilization commenced in February 2001, and plots received one full year of fertilizer before the decomposition experiment began.

Designing an experiment to accurately assess the effects of nutrient availability on organic matter decomposition in a site with 100-200 species per hectare (e.g., Kappelle et al. 2003) represents a serious challenge. For example, foliar and litter nutrient contents of tropical forest tree species vary considerably, both between and within species (A. Townsend and C. Cleveland, unpublished manuscript). Thus, a decomposition experiment with mixed litter (that occupies a range of nutrient contents) precludes a well-controlled test of the effect of nutrient availability on decomposition. To control for foliar nutrients, we decomposed organic material from a single widespread neotropical species, Brosimum utile. While no single species could accurately represent the decomposition dynamics of an entire forest community (especially in a highly diverse tropical rain forest) our goal was to select a species that best represented an "average" species. B. utile is the most common tree species on the Osa Peninsula, is present in tropical rain forests in both Central and 
South America, and has intermediate concentrations of most major nutrients (relative to several other common canopy species in neotropical forests; A. Townsend and C. Cleveland, unpublished manuscript).

Our experimental design included a test of the effects of litter layer organic matter nutrient content on decomposition rates. Consequently, we constructed our decomposition bags using foliage sampled from single B. utile trees growing at AF (ALIT) and UF (ULTLIT) sites; (Appendix B). Decomposition studies are often conducted using recently senesced leaves collected from traps (e.g., Scowcroft et al. 2000). However, the high tree diversity at our forest sites leads to a wide range of species represented in litter traps, litter composition varies considerably between traps, and withinspecies litter nutrient content varies considerably at short time scales (i.e., monthly; A. Townsend and C. Cleveland, unpublished manuscript). Since our goal was to compare soil nutrient (UF vs. AF), organic matter nutrient (ALIT vs. ULTLIT), and nutrient fertilization effects on decomposition, we required large amounts of chemically homogeneous litter. To control for the nutrient content of the organic matter used in the decomposition experiment, we sampled individual B. utile trees in January 2001, (i.e., the dry season, when annual litterfall reaches a maximum; C. Cleveland and A. Townsend, unpublished manuscript) by climbing a $B$. utile tree at both sites, removing limbs from various heights and positions throughout the canopy, and mixing collected foliage. While in some ways this approach may have resulted in unrepresentative "litter" (i.e., organic material that may not have undergone senescence or nutrient resorption), analyses of both $B$. utile foliage and litter collected in litter traps at the time of harvest suggested that the $\mathrm{C}, \mathrm{N}$, and $\mathrm{P}$ content of foliage closely mirrored that of freshly fallen B. utile litter. This approach also provided large quantities of chemically homogeneous material necessary to separate the effects of soil vs. litter nutrients, while still allowing use of a material that was similar to freshly fallen litter.

Following collection, foliage was dried at $50^{\circ} \mathrm{C}$ and $\sim 7 \mathrm{~g}$ were sealed in $15 \times 15 \mathrm{~cm}$ litterbags constructed with $1 \mathrm{~mm}$ mesh fiberglass screen. In April of 2002 (the end of the dry season, and when forest floor litter mass is highest; C. Cleveland and A. Townsend, unpublished manuscript), a total of 1120 decomposition bags were placed on top of the litter layer in plots at UF and AF sites. Bags were separated on strands by at least $15 \mathrm{~cm}$, and were arranged in plots to form an " $\times$," with decomposition bag strands composed of ULTLIT and ALIT, respectively, intersecting at their midpoints. Thus, all plots contained two strands of seven bags; one strand contained ULTLIT, and one strand contained ALIT. Thirty additional bags were also constructed, transported to the field, immediately returned to the laboratory, dried at $70^{\circ} \mathrm{C}$, and weighed to determine $50^{\circ}$ to $70^{\circ} \mathrm{C}$ conversion factors and the effects of handling and transport on litterbag mass. Bags were harvested at $30,60,90,150,180,240$, and $300 \mathrm{~d}$ after being placed in the field and analyzed for mass loss and carbon and nutrient chemistry.

While soil $\mathrm{C}$ and $\mathrm{N}$ content are similar at $\mathrm{AF}$ and UF, the soils at the two sites are markedly different in both total $\mathrm{P}(P<0.001)$ and labile $\mathrm{P}$ content $(P<$ 0.01 ; Appendix A). The differences in $\mathrm{P}$ availability between UF and AF provided an opportunity to investigate the effects of in situ soil $\mathrm{P}$ availability on organic matter decomposition in a diverse mainland tropical rain forest (Appendix A). Thus, the effects of in situ soil $\mathrm{P}$ availability on decomposition were assessed by decomposing common organic substrates in control plots at both sites (Appendix C).

Next, foliar $\mathrm{P}$ concentrations in B. utile were significantly higher $(50 \% ; P<0.001)$ at AF than UF sites, reflecting the higher soil $\mathrm{P}$ availability in the alluvial soil (Appendix B). The difference in foliar P content between $B$. utile individuals growing at AF and UF sites provided an opportunity to investigate the effect of organic matter $\mathrm{P}$ content on decomposition. To test the effects of organic matter $\mathrm{P}$ availability on decomposition, we performed a reciprocal transplant of $B$. utile foliage grown on alluvial soil (ALIT) to UF, and B. utile foliage grown on ultisol soil (ULTLIT) to AF (Appendix C). Finally, we assessed the effects of nutrient fertilization on decomposition by decomposing both ALIT and ULTLIT in fertilized and control plots at both AF and UF. Thus, our experimental design included a full-factorial (soil nutrient $\times$ litter nutrient $\times$ soil fertilization treatment) organic matter decomposition experiment (Appendix C).

\section{Analytical methods: soil}

Soils for chemical and physical analyses were sampled at AF and UF sites from plots (control, N, P, N $+\mathrm{P})$ using a hand soil corer $(6 \times 10 \mathrm{~cm})$. Within 72 $\mathrm{h}$ of collection, soils were returned to the laboratory at the University of Colorado and coarsely sieved (4 $\mathrm{mm}$ ) to remove plant material. 50-g subsamples were removed from each soil and air dried for physical and chemical analyses. Fresh soil samples were stored at $4^{\circ} \mathrm{C}$ until analysis, and incubation experiments were initiated within $96 \mathrm{~h}$ of soil sampling to avoid artifacts incurred during long-term storage.

We measured $\mathrm{pH}$ on air-dried soils using a soil : deionized water paste (1:1). Soil bulk density at each site was determined using an excavation method (Parent and Caron 1993). Soils for organic $\mathrm{C}$ and $\mathrm{N}$ analyses were ground to $\sim 0.5 \mathrm{~mm}$ and analyzed using a Carlo Erba combustion-reduction elemental analyzer (CE Elantech, Lakewood, New Jersey, USA). Extractable $\mathrm{N}\left(\mathrm{NH}_{4}{ }^{+} / \mathrm{NO}_{3}{ }^{-}\right)$was determined in a $2 \mathrm{~mol} / \mathrm{L} \mathrm{KCl}$ solution ( $24 \mathrm{~h}$ extraction), and labile $\mathrm{P}$ was determined by using the first two steps of the modified Hedley fractionation (Tiessen and Moir 1993). $\mathrm{NH}_{4}{ }^{+}, \mathrm{NO}_{3}{ }^{-}$, and $\mathrm{PO}_{4}{ }^{3-}$ in extracts were analyzed colorimetrically 
on an Alpkem autoanalyzer (OI Analytical, College Station, Texas, USA).

\section{Analytical methods: organic matter}

Following collection, decomposition bags were dried in a hothouse in the field and returned to the laboratory at the University of Colorado. After removing adhered debris with a dry brush, bags were dried at $70^{\circ} \mathrm{C}$ and reweighed to determine mass loss. Material from each bag was ground to a fine powder with a mortar and pestle $(\sim 0.5 \mathrm{~mm})$ and analyzed for litter $\mathrm{C}$ and $\mathrm{N}$ content using a Carlo Erba EA 1110 elemental analyzer. Litter $\mathrm{P}$ was assessed using a sulfuric acid/hydrogen peroxide digest and a colorimetric $\mathrm{P}$ analysis on an Alpkem autoanalyzer using the ammonium molybdate ascorbic acid method (Kuo 1996). Calcium, magnesium, and potassium content of organic material were analyzed using an ARL 3410 Inductively Coupled Plasma Atomic Emission Spectrophotometer (ICP-AES; Thermo Electron, Waltham, Massachusetts, USA).

\section{Organic matter solubility}

To assess the potential magnitude of litter layer mass loss via leaching through time, we determined the solubility of decomposing organic matter using a plant fiber analyzer (Ankom Technology, Macedon, New York, USA). Briefly, subsamples from bags harvested at each time point were ground to a fine powder, sealed in filter bags, and digested in a dilute neutral detergent at $100^{\circ} \mathrm{C}$. Following digestion, filter bags were reweighed to determine soluble cell mass loss (Van Soest and Wine 1968, Hobbie and Gough 2004). The C:P ratios of leached dissolved organic matter (DOM) were determined using the same procedure, but using a hot water extraction instead of the neutral detergent. The C content of hot water extractable DOM was determined using a Shimadzu TOC 5050A total organic carbon analyzer (Shimadzu Corporation, Kyoto, Japan), and inorganic $\mathrm{P}$ in leached DOM using an Alpkem autoanalyzer.

\section{Fertilization effects on DOM decomposition}

To determine the effect of nutrient fertilization on litter-leached DOM mineralization in soil, we conducted an incubation experiment using UF soil and soluble $\mathrm{C}$ leached from UF foliage that was used to construct litterbags. $100 \mathrm{~g}$ of dry organic material were extracted in $1 \mathrm{~L}$ of deionized water for $24 \mathrm{~h}$ at $22^{\circ} \mathrm{C}$. Following extraction, leachate was filtered to $0.45 \mu \mathrm{m}$, and $\mathrm{C}$ concentration of the leachate was measured using a Shimadzu TOC 5050A total organic carbon analyzer. Soil samples (15 g dry mass) collected from control, $\mathrm{N}, \mathrm{P}$, and $\mathrm{N}+\mathrm{P}$ plots $(N=10)$ at UF were placed in 1-L glass jars, and given $5 \mathrm{~mL}$ (i.e., an amount to bring soil to $50 \%$ of water holding capacity) of either dissolved organic carbon (DOC; $422 \mu \mathrm{g}$ DOC-C/g soil) or water (as control). Following treatment additions, jars were capped with lids equipped with rubber septa for gas sampling, and sampled for $\mathrm{CO}_{2}$ at 3, 6, 9, 12, $15,24,32$, and $48 \mathrm{~h}$ using glass gas-tight syringes. $\mathrm{CO}_{2}$ concentration was determined immediately using a Shimadzu GC-14 gas chromatograph equipped with a thermal conductivity detector.

\section{Data analysis}

All data were tested for homoscedasticity (Levene's test for equal variances), normality, and skewedness (SPSS, Chicago, Illinois, USA). When data were heterogeneous, they were $\ln$-transformed prior to analysis. Differences in soil nutrients (control plots) and initial foliar nutrients between UF and AF were tested with one-way ANOVA. Annual decomposition rates ( $k$ values) were determined for each litterbag strand (i.e., by site, litter type). Briefly, mass loss data were analyzed using the model of Olson (1963), $y=\mathrm{e}^{-k t}$, where $y$ is the fraction of mass remaining at a specific time $t$ (years). Hence, the basis for our analyses $(k)$ is the negative exponential decay constant. By using this approach, we were able to use all data from all plots to calculate mean decomposition rates for each litterbag strand $(N=160)$, and thus remove the effects of litterbag harvest time from our analyses (Potvin et al. 1990). This strategy produced 10 independent replicate estimates of decay for each treatment (litter $\times$ soil $\times$ fertilization treatment). Differences between decay constants were then analyzed using ANOVA with site, litter type, and fertilization treatment as factors. ANOVA was also used to determine the significance of the three main factors (soil type, litter type, and fertilization) and their interactions on litter decomposition rates $(k)$. To determine the effect of initial litter and soil nutrients and their combined effects on decomposition, we performed ANOVA using soil type and litter type as factors, and using $k$ values obtained in control plots. We also used ANOVA to assess the effect of nutrient fertilization on litter nutrient dynamics, with treatment and harvest date as the main factors. Differences in organic matter solubility through time and respiration rates following DOM additions in the incubation experiment were tested with one-way ANOVA.

\section{REsUlts}

\section{Fertilization effects on soil chemistry}

Phosphorus fertilization caused significant increases in soil labile P pools at both AF and UF sites. After one year of fertilization, UF plots receiving $\mathrm{P}$ or $\mathrm{N}+$ $\mathrm{P}$ had significantly $(P<0.05)$ higher labile $\mathrm{P}(67.7 \pm$ 13.8 and $107.4 \pm 33.5 \mu \mathrm{g} / \mathrm{g}$ soil [dry mass], respectively) than control and N-fertilized plots (19.4 \pm 5.3 and $25.5 \pm 2.7 \mu \mathrm{g} / \mathrm{g}$ soil, respectively). At AF, plots receiving $\mathrm{P}$ or $\mathrm{N}+\mathrm{P}$ also had significantly $(P<0.05)$ higher labile $P(116.8 \pm 40.0$ and $146.2 \pm 34.4 \mu \mathrm{g} / \mathrm{g}$ soil, respectively) than control and $\mathrm{N}$ plots $(25.1 \pm 7.6$ and $33.4 \pm 1.7 \mu \mathrm{g} / \mathrm{g}$ soil, respectively). However, after 
TABle 1. Mean decay rates $(k)$ for Brosimum utile foliage decomposed in the ultisol forest (UF) or alluvial forest (AF) control plots.

\begin{tabular}{cccccc}
\hline \hline & \multicolumn{2}{c}{ ULTLIT } & & \multicolumn{2}{c}{ ALIT } \\
\cline { 2 - 3 } \cline { 5 - 6 } Site & $k$ & $r^{2}$ & & $k$ & $r^{2}$ \\
\hline UF & -2.82 & 0.76 & & -2.51 & 0.84 \\
AF & -4.40 & 0.87 & & -2.95 & 0.84
\end{tabular}

Notes: Decay rate values $(k)$ represent the mean of values calculated from an exponential decay model in control plots over a period of 300 days, and regression coefficient values $\left(r^{2}\right)$ represent the mean of $r^{2}$ values of corresponding litterbag strands. Key to abbreviations: ULTLIT, $B$. utile foliage grown on ultisol soil; ALIT, B. utile foliage grown on alluvial soil.

one year of $\mathrm{N}$ fertilization, extractable $\mathrm{N}$ pools did not differ significantly between treatments at either UF ( $P$ $=0.19)$ or $\mathrm{AF}(P=0.27)$.

Fertilization with $\mathrm{N}$ or $\mathrm{P}$ alone did not significantly affect soil $\mathrm{pH}$ values relative to control plots. However, fertilization with $\mathrm{N}+\mathrm{P}$ caused a significant decrease in soil $\mathrm{pH}$ in both soil types (Tukey's b, $P<0.01$ ). At the end of the decomposition experiment, soil $\mathrm{pH}$ values at UF were $4.85 \pm 0.03,4.75 \pm 0.02,4.69 \pm 0.12$, and $4.48 \pm 0.05$ (mean \pm SE) in the control, N, P, and $\mathrm{N}+$ P plots, respectively. At AF, soil $\mathrm{pH}$ values were $5.58 \pm 0.09,5.39 \pm 0.31,5.70 \pm 0.18$, and $5.05 \pm$ 0.38 in the control, $\mathrm{N}, \mathrm{P}$, and $\mathrm{N}+\mathrm{P}$ plots, respectively.

\section{Organic matter mass loss}

Mass loss rates in decomposition bags at UF and AF sites were extremely rapid. At both sites, most samples lost $>50 \%$ of their mass in $<120 \mathrm{~d}$, and $>90 \%$ of their mass after $300 \mathrm{~d}$ in the field. While mass loss was rapid in all samples, decomposition rates (i.e., $k$ values) did vary significantly by soil (UF vs. AF) and organic matter type (ULTLIT vs. ALIT; Table 1). For example, while initial rates of decomposition ( $0-90 \mathrm{~d})$ in control plots did not vary significantly between UF and AF, over the course of the entire experiment $(300 \mathrm{~d})$ rates were significantly higher at AF than at UF, irrespective of the material being decomposed $(P<0.05)$. Mass loss rates also varied by organic matter type. In particular, the relatively P-rich ALIT decomposed more slowly than the P-poor ULTLIT at both sites, although the difference was only significant at $\operatorname{AF}(P<0.05$; Table 1). The fastest rates were achieved by decomposing the P-poor ULTLIT at the P-rich AF site $(k=$ $-4.4)$, and the slowest rates were observed decomposing ALIT at UF $(k=-2.5$; Table 1$)$.

\section{Nutrient fertilization effects on mass loss}

We expected that $\mathrm{P}$ fertilization would accelerate mass loss rates at the P-poor UF site, but not at the relatively P-rich AF site. However, nutrient fertilization had no effect on mass loss rates (Fig. 1); after 90 and 300 days in the field, calculated $k$ values did not vary significantly by treatment at either site. Moreover, the litter type and soil type effects observed in decomposing material in control plots were not significant in the fertilization plots; mass loss rates were similar, irrespective of site or organic matter type.

While nutrient fertilization did not affect mass loss rates of decomposing organic matter, it did have profound effects on nutrient dynamics through decomposition (Fig. 2). P fertilization caused consistent increases in the $\mathrm{P}$ concentration of the decomposing or-

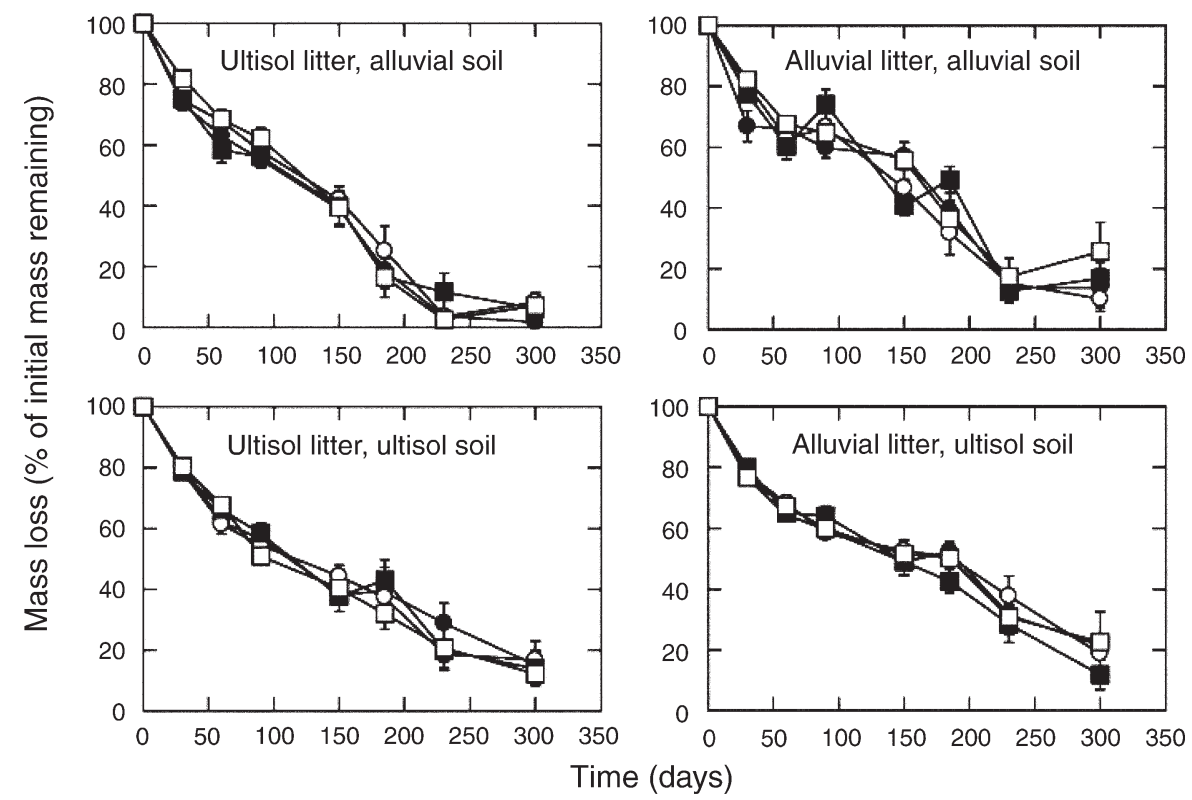

FIG. 1. Effects of nutrient fertilization on loss of organic matter mass shown as percentage of mass remaining (mean \pm $\mathrm{SE}$ ). Treatment types are represented by solid circles (control), open circles ( $\mathrm{N}$ added), solid squares ( $\mathrm{P}$ added), and open squares $(\mathrm{N}+\mathrm{P}$ added). 


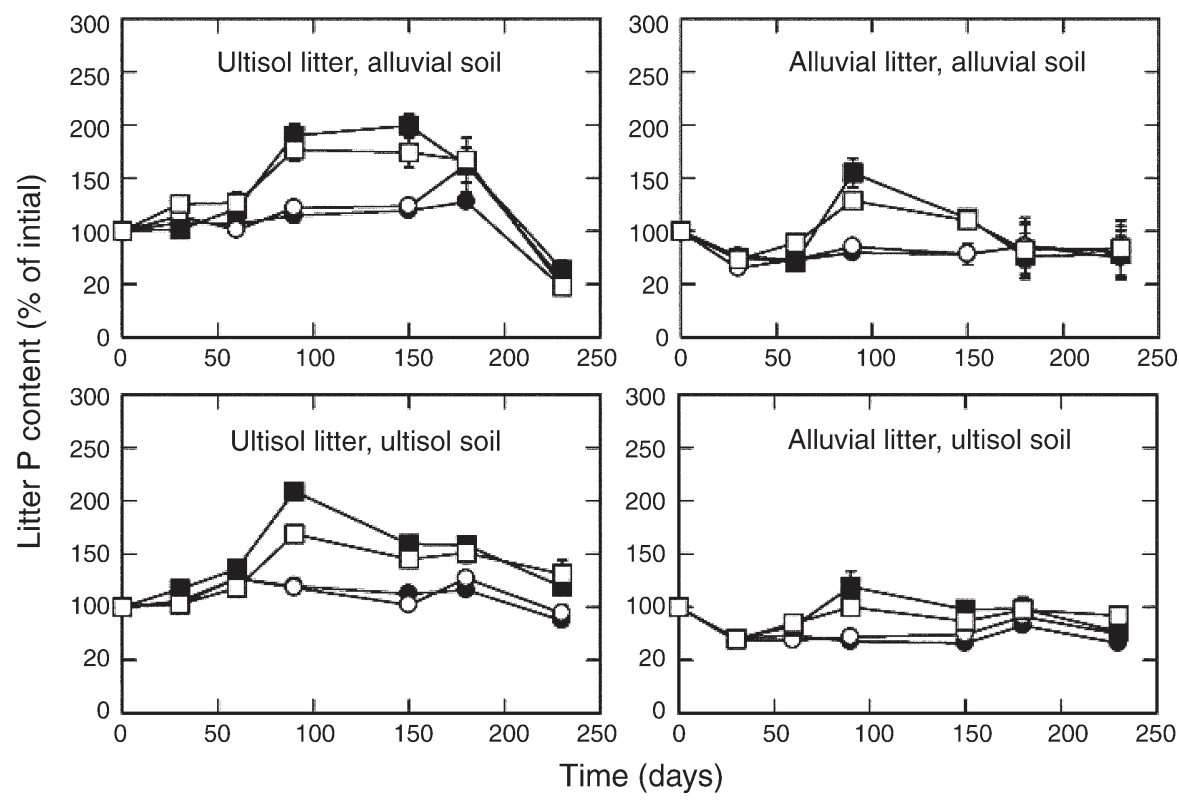

FIG. 2. Effects of nutrient fertilization on the percentage of initial phosphorus (P) remaining in organic matter through time. Treatment types are represented by solid circles (control), open circles ( $\mathrm{N}$ added), solid squares (P added), and open squares $(\mathrm{N}+\mathrm{P}$ added $)$. Values are mean $\pm \mathrm{SE}$.

ganic material at both sites. For example, after $90 \mathrm{~d}$ in the field, material decomposing in $\mathrm{P}$ and $\mathrm{N}+\mathrm{P}$ plots consistently immobilized $\mathrm{P}$, while material decomposing in control and $\mathrm{N}$ plots (at both sites) frequently lost $\mathrm{P}$ (Fig. 2). Increases in organic matter $\mathrm{P}$ content in $\mathrm{P}$ fertilized plots also translated to differences in the proportion of original $\mathrm{P}$ remaining in the organic material through decomposition. After 90 days, organic matter masses in all plots had decreased by $>40 \%$, but material decomposing in plots fertilized with $\mathrm{P}$ or $\mathrm{N}+\mathrm{P}$ in combination contained $120-180 \%$ of their original $P$ mass (Fig. 2). In contrast, material decomposing in control and $\mathrm{N}$ plots retained much of their original $\mathrm{P}$ mass (i.e., 70-110\%), but rarely immobilized P.

\section{Organic matter solubility}

The soluble cell content of decomposing organic material remained high throughout decomposition (Fig. 3 ). Following an initial decrease in the soluble fraction in all bags 30 days after placement in the field, the soluble fraction reformed in bags at both sites and increased as decomposition proceeded (See Appendix E for full solubility table). Initially, $26 \%$ of ULTLIT and ALIT was soluble, and by day 30 , the soluble fraction decreased to $19 \%$ in ULTLIT and $13 \%$ in ALIT (Fig. 3; Appendix E). However, by day 60 , the soluble fraction of decomposing material had regenerated and showed signs of increasing; by the end of the experiment, $32 \%$ of the remaining ALIT and $40 \%$ of the remaining ULTLIT was still soluble.

Phosphorus fertilization not only increased $\mathrm{P}$ immo- bilization in organic matter decomposing in the litter layer, but also caused increases in the dissolved inorganic $\mathrm{P}$ content of the soluble fraction of decaying organic material. For example, over the whole experiment, water soluble inorganic P of leached material (both ALIT and ULTLIT) decomposing in P plots at UF was more than double the value obtained from control plot litter $(0.16$ $\pm 0.03 \mathrm{mg} / \mathrm{g}$ soil vs. $0.07 \pm 0.02 \mathrm{mg} / \mathrm{g}$ soil, respectively; $N=20, P<0.05)$. In contrast, the $\mathrm{C}$ content of organic matter through time did not vary as a function of nutrient availability. Thus, increased dissolved inorganic P concentrations led to corresponding decreases in the $\mathrm{C}: \mathrm{P}$ ratio of soluble DOM leached from material decomposing in the P-fertilized plots.

\section{Nutrient constraints on DOM decomposition}

To test the effects of soil nutrient availability on leached DOM mineralization in soil, we conducted an incubation experiment using DOM leached from ULTLIT and added to UF soil (Fig. 4). Additions of leached DOM to P-fertilized soil elicited significantly higher respiration than corresponding additions to control, $\mathrm{N}$, and $\mathrm{N}+\mathrm{P}$ soils; respired $\mathrm{CO}_{2}$ reached concentrations of $15171 \pm 498 \mu \mathrm{mol} / \mathrm{mol}$ air, while control, $\mathrm{N}$, and $\mathrm{N}+\mathrm{P}$ soils reached $13486 \pm 758,12637$ \pm 136 , and $11710 \pm 269 \mu \mathrm{mol} / \mathrm{mol}$ air, respectively, after $48 \mathrm{~h}(P<0.05)$. Moreover, $\mathrm{CO}_{2}$ evolution rates and cumulative respired $\mathrm{CO}_{2}$ following DOM additions were consistently higher in P-fertilized soil than in other treatments at all time points, and significantly higher at all time points after $6 \mathrm{~h}$ (Fig. $4 ; P<0.05$ ). 


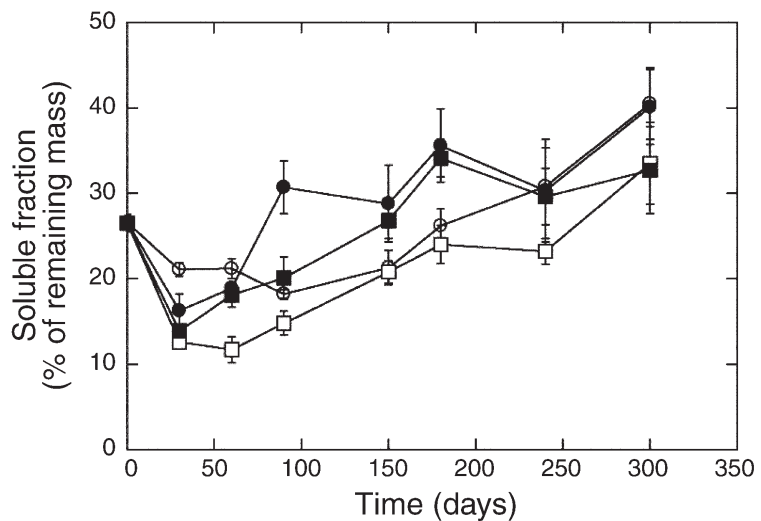

FIG. 3. Changes in the percentage of water-soluble organic matter (mean $\pm \mathrm{SE}$ ) over the decomposition period, 0 300 days. Circles represent solubility of litter from $B$. utile trees grown on ultisol forest soil (ULTLIT), and squares represent litter from $B$. utile trees grown on alluvial forest soil (ALIT). Open symbols represent litter decomposed on ultisol forest soil (UF), and solid symbols represent litter decomposed on alluvial forest soil (AF).

\section{DISCUSSION \\ Organic matter mass loss}

While we expected that mass loss during decomposition would be rapid in this warm wet ecosystem, the mass loss rates we measured were among the highest ever reported. For example, $k$ values (Table 1) were higher than all but one rate (out of 52) generated from decomposing litter from both a temperate and tropical woody species observed as part of the Long term Intersite Decomposition Experiment (LIDET; Gholz et al. 2000). Moreover, the litter type used by Gholz et al. (2000) was higher quality organic material (i.e., lower lignin content and lignin: $\mathrm{N}$ ratios) than the $B$. utile material decomposed in this study (Appendix B), suggesting that this environment is ideal for decomposition. With very few exceptions, the $B$. utile bags lost $>50 \%$ mass in $\sim 150 \mathrm{~d},>80 \%$ mass in $\sim 250 \mathrm{~d}$, and by day 300 of our experiment, $>50 \%$ of our bags had lost $100 \%$ of their original mass. These results contrast strongly with the results of Hobbie and Vitousek (2000), who conducted a similar experiment in Hawaii. In that study, decomposing organic matter took $>2 \mathrm{yr}$ to achieve $>80 \%$ mass loss, though lower rates would be expected given the lower mean annual temperature, mean annual precipitation, and poorer litter quality of the litter decomposed in Hawaii.

Our sites are similar to many other mainland tropical rain forests with respect to tree species diversity and composition, mean annual temperature, geomorphology, and geology. However, with $>5000 \mathrm{~mm}$ of rainfall per year, they lie on the wet end of the tropical rain forest precipitation spectrum. Some work suggests that high inputs of precipitation can decrease decomposition. For example, Schuur (2001) showed that in sites where rainfall varied from 2200 to $>5000 \mathrm{~mm} / \mathrm{yr}$, in situ rates of decomposition decreased by more than a factor of six with increased precipitation. Schuur (2001) attributed the declining rates to lowered oxygen availability in wetter sites. However, the extremely rapid decomposition rates we observed argue against precipitation constraints on decomposition in the Costa Rican sites, and corroborate a growing body of data showing a strong positive relationship between decomposition and precipitation up to $7000 \mathrm{~mm} / \mathrm{yr}$ (J. Powers, personal communication).

We suggest that the high rainfall regime at our sites may be largely responsible for the extremely rapid decomposition rates we observed in this experiment. But how could high precipitation drive such high decomposition rates? Traditional conceptual and simulation models of mass loss during organic matter decomposition have focused primarily on mineralization to $\mathrm{CO}_{2}$ in the litter layer as the dominant mass loss mechanism (Parton et al. 1994). However, decomposition includes another mass loss vector, DOM leaching (Currie and Aber 1997), and recent work has shown that leaching losses can vary with plant litter type (Allison and Vitousek 2004) and with varying precipitation inputs (Currie and Aber 1997). Thus, some current models now link decomposition to the generation and flux of soluble material out of litter to account for this important component of mass loss (e.g., Currie and Aber 1997, Neff and Asner 2001). In this study, we found that following an initial decrease, the soluble fraction of decomposing organic matter stayed high throughout the experiment (Fig. 3; Appendix E). The fact that a soluble $\mathrm{C}$ fraction remained relatively constant also suggests that while episodic precipitation inputs may temporarily deplete soluble $\mathrm{C}$ stocks, the soluble $\mathrm{C}$ fraction in the litter layer is regenerated on relatively short time scales (i.e., hours to days) and is constantly available for transport to the soil.

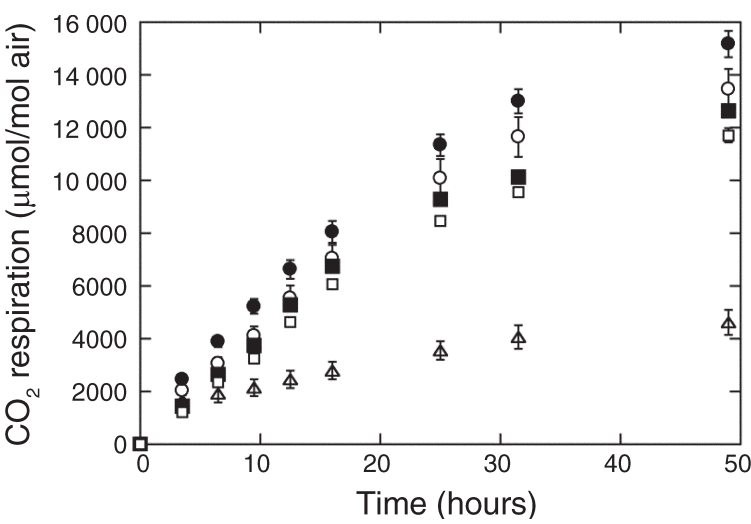

FIG. 4. Soil $\mathrm{CO}_{2}$ fluxes (mean $\pm \mathrm{SE}$ ) following dissolved organic matter additions to control and fertilized soil samples. Soil treatment types are represented by open circles (control), solid circles ( $\mathrm{P}$ added), solid squares ( $\mathrm{N}$ added), and open squares $\left(\mathrm{N}+\mathrm{P}\right.$ added). Open triangles depict $\mathrm{CO}_{2}$ flux in control soil after adding water. 
We suggest that in wet ecosystems, especially in systems with abundant relatively soluble litter, high rainfall may drive substantial transfers of soluble $\mathrm{C}$ from the litter layer to the soil environment as DOM, increasing the proportion of litter layer mass lost via leaching. Moreover, variations in the potential to generate sizable fluxes of DOM from the litter layer may contribute to variations in organic matter mass loss rates across wet ecosystems. In other words, if high rainfall can drive the movement of a substantial DOM flux from the litter layer, mass loss may occur rapidly despite a potential reduction in microbial activity brought on by wetter conditions. However, if the litter is resistant to DOM formation (as the sclerophyllous Hawaiian Metrosideros polymorpha litter studied by Schuur [2001] may well be), then very wet conditions could result in slower mass loss. Certainly the possibility deserves further attention.

Given the control exerted by $\mathrm{P}$ on ecosystem processes in tropical rain forests, we expected that litter layer mass loss would be fastest at alluvial forest (AF), where both total and labile soil $\mathrm{P}$ values are significantly higher than at ultisol forest (UF; Appendix A). We also hypothesized that (1) litter P availability would regulate mass loss rates, (2) litter layer mass loss would be greatest with the P-rich ALIT in the P-rich AF site, and (3) that rates of mass loss would be most constrained by $\mathrm{P}$ availability with ULTLIT at the UF site. While mass loss was rapid irrespective of litter type or site differences, we did observe significant effects of soil type and litter type on rates (Table 1; Appendix D). As expected, the fastest rates were at the P-rich AF site; both ULTLIT and ALIT lost mass faster at AF than either litter type at UF, suggesting that the higher $\mathrm{P}$ availability at AF may contribute to faster rates of mass loss at AF. However, contrary to our expectations, higher litter $\mathrm{P}$ availability did not enhance mass loss rates at either site (Table 1; Appendix D); the P-poor ULTLIT actually lost mass more rapidly than ALIT at AF $(P<0.01)$, and there were no differences in decomposition rates between the two litter types at UF. The lack of a relationship between organic matter P content and mass loss suggests that $\mathrm{P}$ availability does not exert primary control over organic matter mass loss in this system.

There are several possible explanations for the variable responses of mass loss to soil and litter P availability. For example, it is possible that differences in litter quality or litter chemistry (and not P availability per se) may be responsible for differences in mass loss rates between ULTLIT and ALIT. In spite of lower P content, ULTLIT had significantly more foliar nitrogen and magnesium than ALIT (Appendix B), which may have been more important than $\mathrm{P}$ content in driving mass loss. Next, while UF and AF are similar with respect to most important state factors, (e.g., climate, elevation, species composition), it is possible that site differences other than soil $\mathrm{P}$ availability contributed to the contrasting effects of litter vs. soil P availability on loss rates. Finally, it is noteworthy that ULTLIT was consistently more soluble than ALIT throughout the course of the experiment (Fig. 3; Appendix E). If, in this extremely wet system, decomposition is dominated by leaching (as we suggest), then the consistently higher solubility of ULTLIT may have led to the more rapid mass loss of ULTLIT that we observed.

\section{Nutrient fertilization effects on decomposition}

Previous research in tropical rain forests has shown that $\mathrm{P}$ availability can constrain mass loss during decomposition (Hobbie and Vitousek 2000). However, in this study, nutrient additions had no significant effects on litter layer organic matter mass loss at either AF or UF (Fig. 1; Appendix D). While this result seems counterintuitive when viewed only in the context of $P$ availability, it is not surprising given the high rainfall at these sites, and the extremely rapid rates of decomposition we observed. For example, most studies investigating nutrient limitation on mass loss during decomposition have been conducted in drier tropical (or temperate) ecosystems, where the potential for mass loss via leaching is lower. In drier systems, high nutrient demand by active microorganisms mineralizing organic material to $\mathrm{CO}_{2}$ directly in the litter may drive observed nutrient limitation of mass loss commonly observed in other decomposition experiments. Alternatively, in wet systems where the potential for leaching and transport of DOM from litter to soil is greater, nutrient constraints on mass loss in the litter layer are less likely. There, controls such as litter solubility and precipitation inputs (both of which are high in our sites) may exert greater control on mass loss. In other words, in wet ecosystems with seasonally large litter pools, leaching losses of $\mathrm{C}$ from the litter layer may outpace $\mathrm{C}$ mineralization in the litter layer. If so, nutrient constraints on decomposition may be most pronounced at the site of $\mathrm{C}$ delivery and $\mathrm{C}$ mineralization, which is the soil (Fig. 5).

Our results show that soil nutrients regulate $\mathrm{C}$ mineralization of DOM leached from the litter layer to the soil. In our incubation study, $\mathrm{P}$ fertilization led to a significant increase in the proportion of added DOM that was converted to $\mathrm{CO}_{2}$ (Fig. 4). The strong effects of $\mathrm{P}$ availability on the rate of DOM mineralization in soil suggest that $\mathrm{P}$ fertility may influence the ultimate fate of leached DOM that enters the soil (Fig. 5). In particular, our results indicate that soil nutrient fertility may influence ecosystem $\mathrm{C}$ balance by regulating the proportion of leached $\mathrm{C}$ that is quickly lost from an ecosystem (via microbial respiration) or that persists within an ecosystem (e.g., via soil stabilization and storage; Cleveland et al. 2002; C. Cleveland and A. Townsend, unpublished manuscript).

In contrast to $\mathrm{P}$ fertilization, our data indicate that $\mathrm{NH}_{4} \mathrm{NO}_{3}$ fertilization may have inhibited soluble $\mathrm{C}$ decomposition over the course of our incubation exper- 


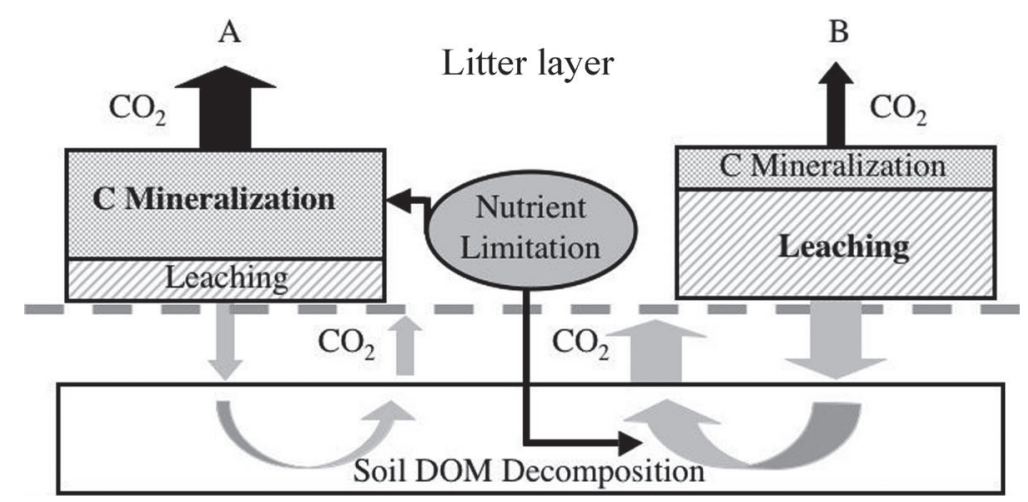

FIG. 5. Conceptual model of the effects of nutrients on decomposition in systems where mass loss from the litter layer is dominated by (A) C mineralization, or (B) leaching losses of dissolved organic matter (DOM) to the soil. Nutrient availability may constrain mass loss directly if most $\mathrm{C}$ mineralization occurs in the litter layer (A). However, in systems with high precipitation and/or highly water-soluble litter, nutrient availability may not limit mass loss (B), but may ultimately regulate DOM mineralization in the soil. The size of the solid arrows represents the relative flux of either $\mathrm{CO}_{2}$ (black arrows) or leached DOM (gray arrows).

iment. Over the first $24 \mathrm{~h}$ of the incubation, there were no significant differences in respiration between control, N, and $\mathrm{N}+\mathrm{P}$ amended samples (Fig. 4). However, after $32 \mathrm{~h}$, respiration in soils amended with $\mathrm{N}$ and $\mathrm{N}$ $+\mathrm{P}$ were significantly lower than control and $\mathrm{P}$ samples (Fig. 4). While we have no evidence that soil microbial respiration is $\mathrm{N}$ limited at UF (and therefore would not expect increased $\mathrm{N}$ availability to stimulate soil respiration), the fact that respiration in both $\mathrm{N}$ and $\mathrm{N}+$ $\mathrm{P}$ samples was significantly lower $(P<0.05)$ than control and $\mathrm{P}$ samples by the end of the experiment (32$48 \mathrm{~h}$ ) suggests that $\mathrm{N}$ had negative effects on DOM respiration. This result is consistent with those commonly observed in several other ecosystems when adding labile C to N-fertilized soil (Fog 1988).

While nutrient fertilization had no significant effect on mass loss during decomposition, it did alter litter nutrient dynamics through time, with potentially profound effects on leached DOM decomposition in soil. In particular, material decomposed in plots amended with $\mathrm{P}$ or $\mathrm{N}+\mathrm{P}$ had significantly higher $\mathrm{P}$ concentrations than plots with no $\mathrm{P}$ amendments, suggesting microbial immobilization of $\mathrm{P}$ during decomposition in the P-amended plots (Fig. 2). Previous work has shown that fertilization can induce microbial nutrient uptake without simultaneous effects on litter mass loss rates (McGroddy et al. 2004). Microbial immobilization of rare elements is likely an important nutrient retention mechanism in nutrient-poor systems (Stark and Jordan 1978, Cleveland et al. 2004, Olander and Vitousek 2004). Our data corroborate previous observations that decomposers are able to retain or take up additional $\mathrm{P}$ when it is readily available, even when additional $\mathrm{P}$ immobilization does not appear to affect mass loss. However, the decline in $\mathrm{P}$ immobilization at later stages of decomposition suggests that as available $\mathrm{C}$ content of remaining litter approaches zero, microbial demand for $\mathrm{P}$ (and hence $\mathrm{P}$ immobilization) also decrease.
While increased P immobilization in P-rich soil may not affect mass loss per se, our data indicate that it may ultimately lead to increased $\mathrm{C}$ mineralization in soil. For example, high $\mathrm{P}$ immobilization in the $\mathrm{P}$ plots led to a concomitant increase in the $\mathrm{P}$ content of the soluble fraction of organic material throughout decomposition, resulting in declines in the $\mathrm{C}: \mathrm{P}$ ratios of soluble DOM. A lower C:P ratio of the leached DOM fraction as a result of $\mathrm{P}$ fertilization could thus lead to faster rates of DOM decomposition and soil respiration by the P-limited soil microbial community. In other words, the site of P-limited $\mathrm{C}$ mineralization (i.e., in the litter layer or in the soil) is not as important as the fact that ultimately, in P-limited systems, greater $\mathrm{P}$ availability stimulates respiratory losses of $\mathrm{CO}_{2}$, and increases the proportion of $\mathrm{C}$ that is rapidly respired during decomposition.

Finally, in wet ecosystems where DOM transport is a major component of litter mass loss, there may be strong and somewhat unique feedbacks between low nutrient availability and decomposition that would not be revealed by focusing on litter mass loss dynamics alone. For example, low $\mathrm{P}$ availability constrained mineralization of soluble C in the P-poor UF soil (Fig. 4). Thus, in wet ecosystems, if high rainfall causes a large fraction of litter $\mathrm{C}$ to be transported to soil as DOM, its ultimate fate likely will depend on soil available $\mathrm{P}$ levels, and the controls over decomposition of that original litter $\mathrm{C}$ become much different once it reaches the soil environment. Here, competition for available $\mathrm{P}$ occurs not only between plants and microbial communities, but also with geochemical sinks for labile P that are created by the clay-rich tropical soils (Uehara and Gillman 1981, Olander and Vitousek 2004). As such, $\mathrm{P}$ constraints for a given amount of $\mathrm{C}$ may be greater if that $\mathrm{C}$ is decomposed in the soil rather than in the litter layer, thereby creating greater microbial immobilization, and feedbacks to even lower P availability 
and nutrient turnover. The reduced decomposition and nutrient turnover that is sometimes observed in very wet sites may not only be a function of lower oxygen availability (Schuur 2001), but also of feedbacks created by moving $\mathrm{C}$ from litter to soils. This hypothesis is consistent with much of our data from the UF site, where low $\mathrm{P}$ soil does not hinder rapid litter mass loss, but where it does create low foliar P concentrations, (A. Townsend and C. Cleveland, unpublished manuscript), limits free-living N fixation (S. Reed, C. Cleveland, and A. Townsend, unpublished manuscript), and constrains the decomposition of leached soluble $\mathrm{C} \mathrm{ob-}$ served here (Fig. 4).

\section{Conclusions}

Several analyses suggest that tropical forests may currently be $\mathrm{C}$ sinks, and absorbed much of the anthropogenic $\mathrm{CO}_{2}$ emitted during the 1990s (Phillips et al. 1998, Malhi and Grace 2000, Townsend et al. $2002 b$ ). However, this conclusion is not widely accepted, and recent data suggest significant net $\mathrm{C}$ loss from intact tropical forests (Clark 2002, Loescher et al. 2003, Saleska et al. 2003). Given the importance of tropical forests in the global carbon budget, it is critical that we understand the factors that regulate $\mathrm{C}$ cycling in these ecosystems. Recent analyses have focused on the role of climate and disturbance in regulating ecosystem $\mathrm{CO}_{2}$ exchange (Cox et al. 2000), but despite the importance of nutrient limitation to $\mathrm{C}$ sequestration in mid-latitude ecosystems (Schimel 1995), the role of nutrient limitation in regulating the $\mathrm{C}$ balance of tropical ecosystems has not been well established.

This study demonstrates that methods commonly used for determining organic matter decomposition rates (i.e., mass loss) may not provide complete insight into the actual importance of nutrient availability in regulating $\mathrm{C}$ losses in wet ecosystems. Instead, our data indicate that assessing the effects of nutrient availability on decomposition requires not only estimates of organic matter mass loss rates, but also estimates of the importance of leaching during decomposition. Moreover, our data indicate that while nutrient availability may not affect mass loss, it may ultimately regulate ecosystem $\mathrm{C}$ losses by regulating the proportion of leached DOM that is microbially respired to $\mathrm{CO}_{2}$. Thus, a more complete picture of the $\mathrm{C}$ balance of tropical forests will require continued efforts to elucidate the extent to which nutrients regulate the decomposition of both insoluble and soluble forms of $\mathrm{C}$ in these C-rich ecosystems.

\section{ACKNOWLEDGMENTS}

We are grateful to Dan Liptzin, Rebecca Rawlinson, and two anonymous reviewers for comments and suggestions that greatly improved the manuscript. We thank $\mathrm{H}$. and M. Michaud of Drake Bay for providing field access and logistical support in Costa Rica, and Francisco Campos and the Organización para Estudios Tropicales (OET) and the Ministerio de Ambiente y Energia (MINAE) in Costa Rica for assisting with research permits and logistics. Briana Constance, Colin
Mann, and Lauren Schevets helped with all phases of the lab work, and Carl Bern, Dan Liptzin, Trevor Popp, and Diana Nemergut assisted with field sampling. This work was supported by a grant from the National Science Foundation (NSF Grant DEB-0089447).

\section{Literature Cited}

Aber, J. D., J. M. Melillo, K. J. Nadelhoffer, J. Pastor, and R. D. Boone. 1991. Factors controlling nitrogen cycling and nitrogen saturation in northern temperate forest ecosystems. Ecological Applications 1:303-315.

Allison, S. D., and P. M. Vitousek. 2004. Extracellular enzyme activities and carbon chemistry as drivers of tropical plant litter decomposition. Biotropica 36:285-296.

Bern, C. R., A. R. Townsend, and G. L. Farmer. 2005. Unexpected dominance of parent-material strontium in a tropical forest on highly weathered soils. Ecology 86:626-632.

Chapin, F. S. I., P. A. Matson, and H. A. Mooney. 2002. Principles of terrestrial ecosystem ecology. Springer, New York, New York, USA.

Clark, D. A. 2002. Are tropical forests an important carbon sink? Reanalysis of the long-term plot data. Ecological Applications 12:3-7.

Cleveland, C. C., A. R. Townsend, B. C. Constance, R. E. Ley, and S. K. Schmidt. 2004. Soil microbial dynamics in Costa Rica: seasonal and biogeochemical constraints. Biotropica 36:184-195.

Cleveland, C. C., A. R. Townsend, and S. K. Schmidt. 2002. Phosphorus limitation of microbial processes in moist tropical forests: evidence from short-term laboratory incubations and field experiments. Ecosystems 5:680-691.

Cox, P. M., A. R. Betts, C. D. Jones, S. A. Spall, and I. J. Totterdell. 2000. Acceleration of global warming due to carbon-cycles feedbacks in a coupled climate model. Nature 408:184-187.

Currie, W. S., and J. D. Aber. 1997. Modeling leaching as a decomposition process in humid montane forests. Ecology 78: $1844-1860$.

Field, C. B., M. J. Behrenfeld, J. T. Randerson, and P. Falkowski. 1998. Primary production of the biosphere: integrating terrestrial and oceanic components. Science 281: 237-240.

Fog, K. 1988. The effect of added nitrogen on the rate of decomposition of organic matter. Biological Reviews 63: 433-462.

Gholz, H. L., D. A. Wedin, S. M. Smitherman, M. E. Harmon, and W. J. Parton. 2000. Long-term dynamics of pine and hardwood litter in contrasting environments: toward a global model of decomposition. Global Change Biology 6:751765 .

Herbert, D. A., and J. H. Fownes. 1995. Phosphorus limitation of forest leaf area and net primary production on a highly weathered soil. Biogeochemistry 29:223-235.

Hobbie, S. E., and L. Gough. 2004. Litter decomposition in moist acidic and non-acidic tundra with different glacial histories. Oecologia 140:113-124.

Hobbie, S. E., and P. M. Vitousek. 2000. Nutrient limitation of decomposition in Hawaiian forests. Ecology 81:18671877.

Kappelle, M., C. Marco, H. Acevedo, L. Gonzalez, and H. Monge. 2003. Ecosistemas del area de conservacion Osa (ACOSA). Instituto Nacional de Biodiversidad, San José, Costa Rica.

Kuo, S. 1996. Phosphorus. Pages 869-919 in D. L. Sparks, editor. Methods of soil analysis. Part 3. Chemical methods. Soil Science Society of America, Madison, Wisconsin, USA.

Loescher, H. W., S. F. Oberbauer, H. L. Gholz, and D. B. Clark. 2003. Environmental controls on net ecosystemlevel carbon exchange and productivity in a Central Amer- 
ican tropical wet forest. Global Change Biology 9:396412.

Malhi, Y., and J. Grace. 2000. Tropical forests and atmospheric carbon dioxide. Trends in Ecology and Evolution 15:332-337.

Martinelli, L. A., M. C. Piccolo, A. R. Townsend, P. M. Vitousek, E. Cuevas, W. McDowell, G. P. Robertson, O. C. Santos, and K. Treseder. 1999. Nitrogen stable isotopic composition of leaves and soil: tropical versus temperate forests. Biogeochemistry 46:45-65.

McGroddy, M. E., W. L. Silver, and J. R. Cosme de Oliveira. 2004. The effect of phosphorus availability on decomposition in a seasonal lowland Amazonian forest. Ecosystems 7:172-179.

Meentemeyer, V. 1978. Macroclimate and lignin control of litter decomposition rates. Ecology 59:465-472.

Melillo, J. M., J. D. Aber, and J. F. Muratore. 1982. Nitrogen and lignin control of hardwood leaf litter decomposition dynamics. Ecology 63:621-626.

Neff, J. C., and G. P. Asner. 2001. Dissolved organic carbon in terrestrial ecosystems: synthesis and a model. Ecosystems 4:29-48.

Oberson, A., D. K. Friesen, C. Morel, and H. Tiessen. 1997. Determination of phosphorus released by chloroform fumigation from microbial biomass high $\mathrm{P}$ sorbing tropical soils. Soil Biology and Biochemistry 29:1579-1583.

Olander, L. P., and P. M. Vitousek. 2004. Biological and geochemical sinks for phosphorus in soil from a wet tropical forest. Ecosystems 7:404-419.

Olson, J. S. 1963. Energy storage and the balance of producers and decomposers in ecological systems. Ecology 44 : 322-331.

Parent, L. E., and J. Caron. 1993. Physical properties of organic soils. Pages 441-458 in M. R. Carter, editor. Soil sampling and methods of analysis. Lewis Publishers, Boca Raton, Florida, USA.

Parton, W. J., D. S. Schimel, D. S. Ojima, and C. V. Cole. 1994. A general model for soil organic matter dynamics: sensitivity to litter chemistry, texture and management. Pages 147-167 in R. B. Bryant and R. W. Arnold, editors. Quantitative modeling of soil forming processes. Soil Science Society of America Special Publication 39. ASA, CSSA and SSA, Madison, Wisconsin, USA.

Phillips, O. L., Y. Malhi, N. Higuchi, W. F. Laurance, P. V. Núñez, R. M. Vásquez, S. G. Laurence, L. V. Ferreira, M. Stern, S. Brown, and J. Grace. 1998. Changes in the carbon balance of tropical forests: evidence from long-term plots. Science 282:439-442.

Potvin, C., M. J. Lechowicz, and S. Tardif. 1990. The statistical analysis of ecophysiological response curves obtained from experimental measurements involving repeated measures. Ecology 71:1389-1400.

Saleska, S. R., et al. 2003. Carbon in Amazon forests: unexpected seasonal fluxes and disturbance-induced losses. Science 302:1554-1557.
Sanchez, P. A., D. E. Brandy, J. H. Villachica, and J. J. Nicholaides. 1982. Amazon Basin soils: management for continuous crop production. Science 216:821-827.

Schimel, D. S. 1995. Terrestrial ecosystems and the carbon cycle. Global Change Biology 1:77-91.

Schuur, E. A. G. 2001. The effect of water on decomposition dynamics in mesic to wet Hawaiian montane forests. Ecosystems 4:259-273.

Scowcroft, P. G., D. R. Turner, and P. M. Vitousek. 2000. Decomposition of Metrosideros polymorpha leaf litter along elevational gradients in Hawaii. Global Change Biology 6:73-85.

Shukla, J., C. Nobre, and P. Sellers. 1990. Amazon deforestation and climate change. Science 247:1322-1325.

Stark, N. M., and C. F. Jordan. 1978. Nutrient retention by the root mat of an Amazonian rain forest. Ecology 58:434437.

Swift, M. J., O. W. Heal, and J. M. Anderson. 1979. Decomposition in terrestrial ecosystems. University of California Press, Berkeley, California, USA.

Tiessen, H., and J. O. Moir. 1993. Characterization of available P by sequential extraction. Pages $75-86$ in M. R. Carter, editor. Soil sampling and methods of analysis. Lewis Publishers, Boca Raton, Florida, USA.

Townsend, A. R., G. P. Asner, C. C. Cleveland, M. E. Lefer, and M. M. C. Bustamante. 2002a. Unexpected changes in soil phosphorus dynamics following tropical deforestation to cattle pasture. Journal of Geophysical Research 107(D20):8067.

Townsend, A. R., G. P. Asner, and J. W. C. White. $2002 b$. Land use effects on atmospheric ${ }^{13} \mathrm{C}$ imply a sizable terrestrial $\mathrm{CO}_{2}$ sink in tropical latitudes. Geophysical Research Letters 19.

Townsend, A. R., P. M. Vitousek, and E. A. Holland. 1992. Tropical soils could dominate the short-term carbon cycle feedbacks to increased global temperatures. Climatic Change 22:293-303.

Uehara, G., and G. Gillman. 1981. The mineralogy, chemistry, and physics of tropical soils with variable charge clays. Westview Press, Boulder, Colorado, USA.

Van Soest, P. J., and R. H. Wine. 1968. Determination of lignin and cellulose in acid detergent fiber with permanganate. Journal Association Office Analytical Chemistry 51:780-787.

Vitousek, P. M. 1984. Litterfall, nutrient cycling, and nutrient limitation in tropical forests. Ecology 65:285-298.

Vitousek, P. M., and R. W. Howarth. 1991. Nitrogen limitation on land and sea: how can it occur? Biogeochemistry 13:87-115.

Vitousek, P. M., and R. L. Sanford. 1986. Nutrient cycling in moist tropical forest. Annual Review of Ecology and Systematics 17:137-167.

Walker, T. W., and J. K. Syers. 1976. The fate of phosphorus during pedogenesis. Geoderma 15:1-19.

Yavitt, J. B., and T. J. Fahey. 1986. Litter decay and leaching from the forest floor in Pinus contorta (lodgepole pine) ecosystems. Journal of Ecology 74:525-545.

\section{APPENDIX A}

Table showing study site characteristics (Ecological Archives E087-027-A1).

\section{APPENDIX B}

Table showing initial foliar chemistry (Ecological Archives E087-027-A2).

\section{APPENDIX C}

Schematic representation of the experimental design (Ecological Archives E087-027-A3). 
APPENDIX D

Three-way ANOVA table showing results for the effects of soil type, litter type, and fertilization on annual decomposition rate, $k$ (Ecological Archives E087-027-A4).

\section{APPENDIX E}

Table showing soluble fraction of litter through time (Ecological Archives E087-027-A5). 